Original Research Article

\title{
Evaluation of self medication practices in common illness among non health care professionals in a tertiary care hospital
}

\author{
Jyothsna Guduru, T. Rohit Singh*, Somnath Motgi, Jamuna Rani
}

Department of Pharmacology, Malla Reddy Institute of Medical Sciences, Hyderabad, Telangana, India

Received: 04 August 2017

Received: 18 August 2017

Accepted: 21 August 2017

*Correspondence to:

Dr. T. Rohit Singh,

Email: rohithsingh3100@

gmail.com

Copyright: () the author(s), publisher and licensee Medip Academy. This is an openaccess article distributed under the terms of the Creative Commons Attribution NonCommercial License, which permits unrestricted noncommercial use, distribution, and reproduction in any medium, provided the original work is properly cited.

\begin{abstract}
Background: Many studies have investigated the prevalence of self medication practices. World health organization promotes the practice of self medication for relief of symptoms without medical consultation to reduce the burden on health care services. Majority of the individuals in developing country like India have poor knowledge about appropriate use of self mediction, but still they practice taking it without knowing the benefits and risk factors.

Methods: The present study was a cross sectional study aimed to gather information about prevalence of self medication in common illness among non health care professionals in a tertiary care hospital. The sample size comprised of 215 participants. Data was collected through an open ended semi structured questionnaire. All the descriptive data was coded, entered in micro soft excel and analysed with frequencies and proportions.

Results: The prevelance of self medication was found to be $96 \%$. Near about $30 \%$ of participants got information from pharmacist regarding self medication. $27 \%$ participants followed allopathy medicine. $16 \%$ participants used becosules and mucaine gel for mouth and throat ulcers. $26 \%$ participants used D-cold total for cough and cold. $15 \%$ participants used dolo $650 \mathrm{mg}$ for fever and headache. $41.7 \%$ participants used ciprofloxacin for ear and eye infections. $26.6 \%$ participants used gelusil for GI infection $.25 .7 \%$ participants used calamine lotion for skin infections and $48 \%$ participants used turmeric for other minor ailments as self medication medicines.

Conclusions: As the prevalence of self medication is high among educated participants. The present study suggest the growing trend of self medication has to be prevented by applying strong policies and prohibiting the supply of medicines without a valid prescription.
\end{abstract}

Keywords: Non health care professionals, Over the counter drugs, Self medication

\section{INTRODUCTION}

Self medication is an important self care practice which can be defined as "the use of drugs to treat self diagnosed disorders or symptoms" or intermittent or continuous use of medication for chronic or recurring disease or symptom. ${ }^{1,2}$ The practice of self medication is very common in many parts of the world, including India. ${ }^{3,4}$

The self medication hypothesis (SMH) originated in papers by Edward Khantzian, Mac and Schatzber. ${ }^{5}$ David
F. Duncan initially focused on heroin and cocaine use and later expanded the use of alcohol and other drugs of addiction for self medication..$^{6-8}$ The world health organization have promoted many reports and cited that self medication is one of the common problem leading to incorrect use of medicines. ${ }^{9}$ In country like india the availability of drugs have become very easy due to their wide range of distribution with inadequate health services which has lead to increased proportions of drugs as self medication compared to prescribed medications by physicians. ${ }^{10}$ 
Medicines used for self medications are also known as "over the counter drugs" medications which are available without prescriptions which are proved of efficacy and safety, where their side effects and interactions have serious complications. ${ }^{11-13}$ A patient with fever, cold, cough, diarrhea, indigestion might receive an expert advice from friends or strangers in India. Urge of self care, lack of health services, poverty, ignorance, extensive and vast advertisement of drugs and more availability of drugs at an establishment other than pharmacies. All these factors govern tremendous growth of self medication over the decade. ${ }^{14}$ Self medication patters vary among different populations and are influenced by many factors apart from which age, sex, income and medical knowledge also plays a pivotal role. ${ }^{15,16}$ In particular self medication is more common in health care professionals (e.g. physicians, nurses and pharmacist) than general public. ${ }^{17}$ Thus there is a need to provide adequate information to population so that they choose right medicine for particular illness to gain benefits from self medication. Hence this study was planned to find the pattern and prevalence of self medication in non health care professionals working in tertiary care hospital in common illness viz; mouth and throat ulcers, common cold and cough, headache and fever, GI infections, eye/ear infections and skin and related infections.

\section{METHODS}

The study was conducted at Malla Reddy Health City, Hyderabad, Telangana, India

\section{Study design}

It was a cross sectional, observational study. For the study protocol, self medication was defined as taking of drugs without prescription (i.e. drugs sold without prescription, OTC drugs). The socio-demographic profile of participants, source of drug information, type of medicine system used, perceptions about self medications, commonly used drugs as self medication in common illness were the parameters used to assess the prevalence of self medication.

\section{Inclusion criteria}

Participants working at Malla Reddy Health City above the age of 18 years of either sex from non health care background v.i.z. office in charge/clerks, computer operators, sweepers, attenders, security guards and receptionist; who took self medication in common illness were included in the study.

\section{Exclusion criteria}

Participants who were not seeking self medication and who were not willing to answer the study questionnaire were excluded from the study.
The pregnant women and participants who were not working in the Malla Reddy Health City were not included in the study.

Health care professionals like doctors and other Para medical staff like nurses, pharmacist, techinians were excluded from the study.

\section{Study tools}

The study was conducted for a period of 2 months and a total of 215 participants were enrolled during the study period. Participants were explained about the study and informed consent was taken in both English and regional language (Telugu). An open ended, semi structured questionnaire both in English language and regional language (Telugu) was distributed to the participants and they were asked to read and fill the questionnaire leaflets. One part of the questionnaire collected the information on socio-demographic profile of the study participants including the source of information about self medication and type of medicine system used and perceptions about self medication. Second part of questionnaire collected information about the drugs/medicines used in common illness i.e. drugs used for mouth and throat ulcers, drugs used in common cold and cough, drugs used for headache and fever, drugs used in ear/eye infections, GIT infections, drugs used for skin and relative infections and any other medications used. Participants who were illiterate were educated about various issues mentioned in the study questionnaire and they were interviewed about the pattern of self medication in common illness and then the questionnaire was filled irrespective of generic names and trade names of medicines.

\section{Statistical analysis}

All the descriptive data was coded, entered in micro soft excel and analysed with frequencies and proportions using SPSS software.

\section{RESULTS}

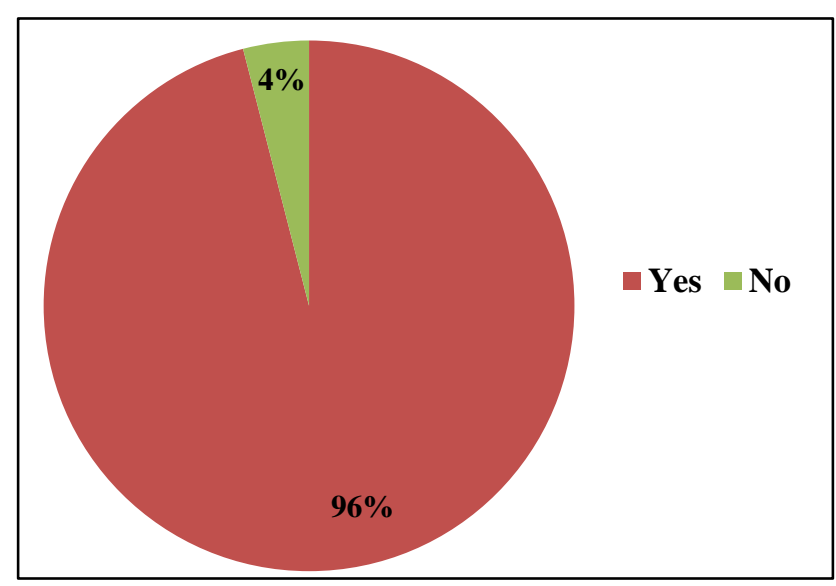

Figure 1: Prevalence of self medication. 
The prevalence of self medication was found to be $96 \%$ in the present study (Figure 1). The study was carried out in 215 non health care participants of which 206 participants reported to take self medication. Of 206 participants 126 were Men and 80 were Women. Of all 11 were post graduates, 20 were graduates, 42 were of intermediate qualification, 38 were of high school qualification, 18 were of middle school qualification, 53 were of primary school qualified and 24 participants were illiterate who were on self medication for common illness (Figure 2).

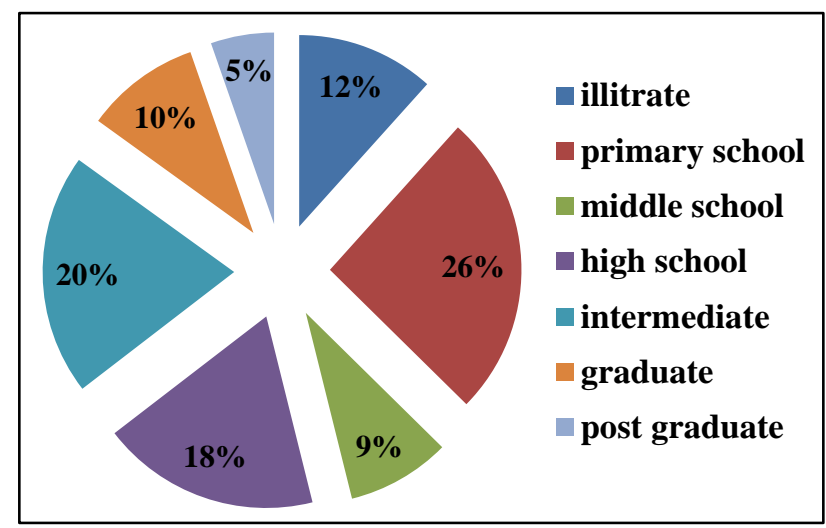

Figure 2: Sociodemographic details of study participants.

Source of information - 30\% participants seek information from pharmacist regarding self medication in common illness, $20 \%$ participants seek information from friends, $25 \%$ from parents, $10 \%$ through advertisement and $9 \%$ participants take self decision for consuming medicines as self medication for common illness Figure 3.

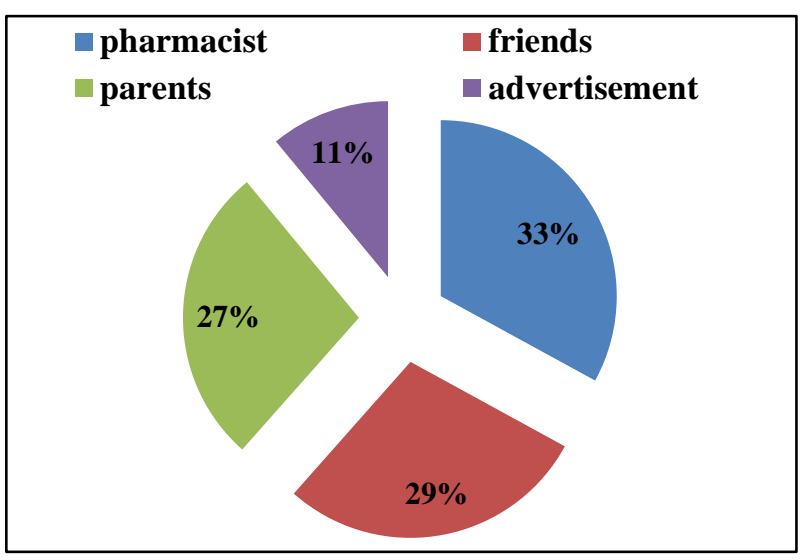

Figure 3: Source of drug information.

\section{Type of medicine system used}

$27 \%$ of study participants take allopathy medicines, $15 \%$ participants take homeopathy medicines, $6 \%$ participants take Ayurveda and 2\% consume other medications (Figure 4).

Drugs used for mouth and throat ulcers - $4 \%$ of participants use candid gel, $8 \%$ take smile gel, $2 \%$ take glycerine, $16 \%$ consume becosules tablets, $16 \%$ apply mucaine gel and $4 \%$ uses chlorhexidine mouth wash (Figure 5).

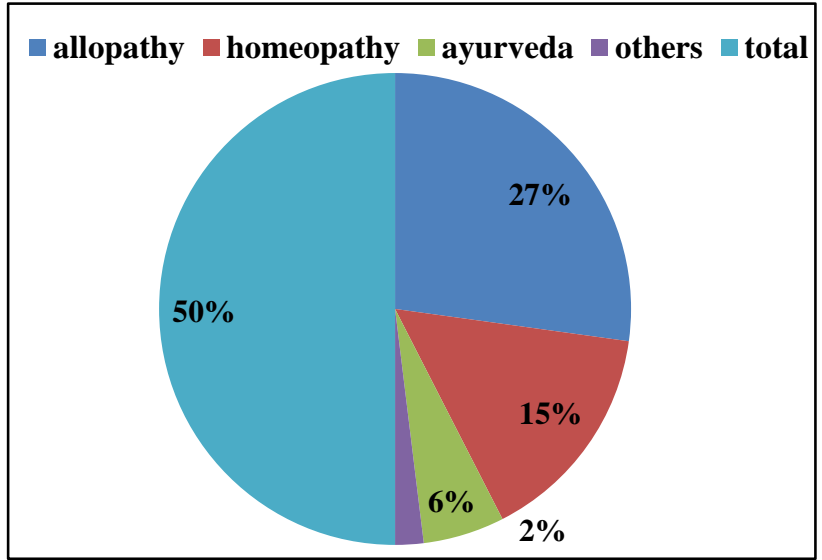

Figure 4: Type of medicine system.

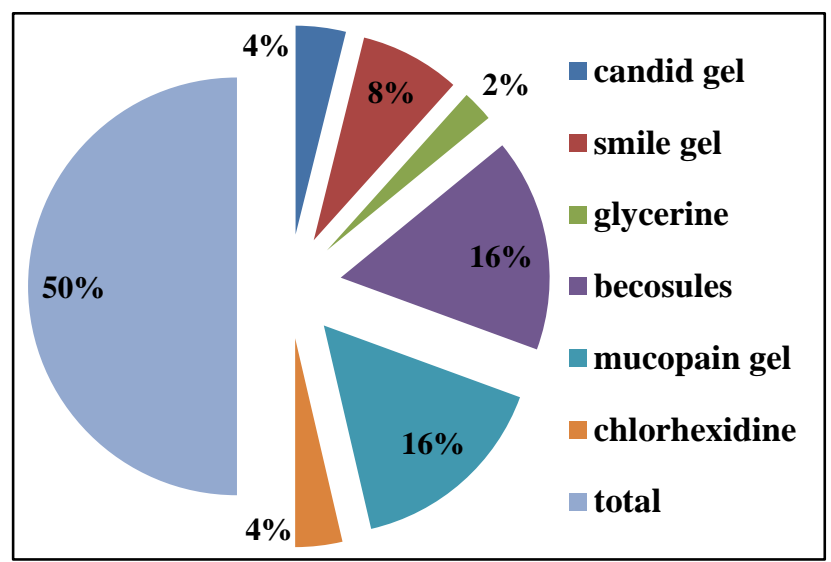

Figure 5: Drugs used for mouth and throat ulcers.

Drugs used for cough and cold - 26\% participants used Dcold total, 24\% used cetrizine, 5\% used sinarest tablets, $10 \%$ used vicks action, $6 \%$ used Benadryl syrup, $7 \%$ used honeytuss cough syrup, $3 \%$ used zinda tilismarc, $8 \%$ vicks vaporub, $4 \%$ used carvolplus for self medication (Figure $6)$.

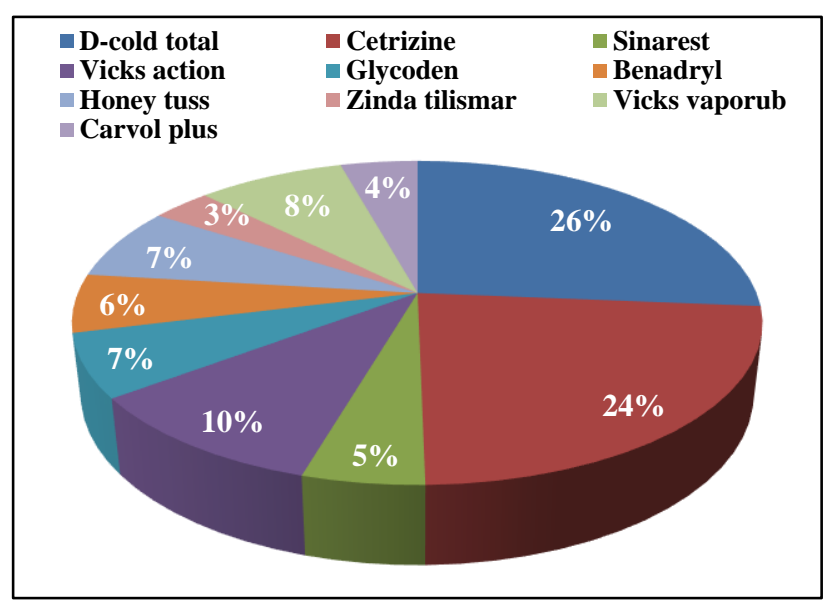

Figure 6: Drugs for cold and cough. 


\section{Drugs used for fever and headache}

For fever and headache $15 \%$ of participants uses dolo $650 \mathrm{mg}, 10 \%$ used crocin, $3 \%$ used combiflam, $2 \%$ used calpol tablets, 15 used dolomet tablets, $4 \%$ used dispirin, $1 \%$ used anacin, $2 \%$ used vicks action 500, $2 \%$ used amixide (Figure 7).

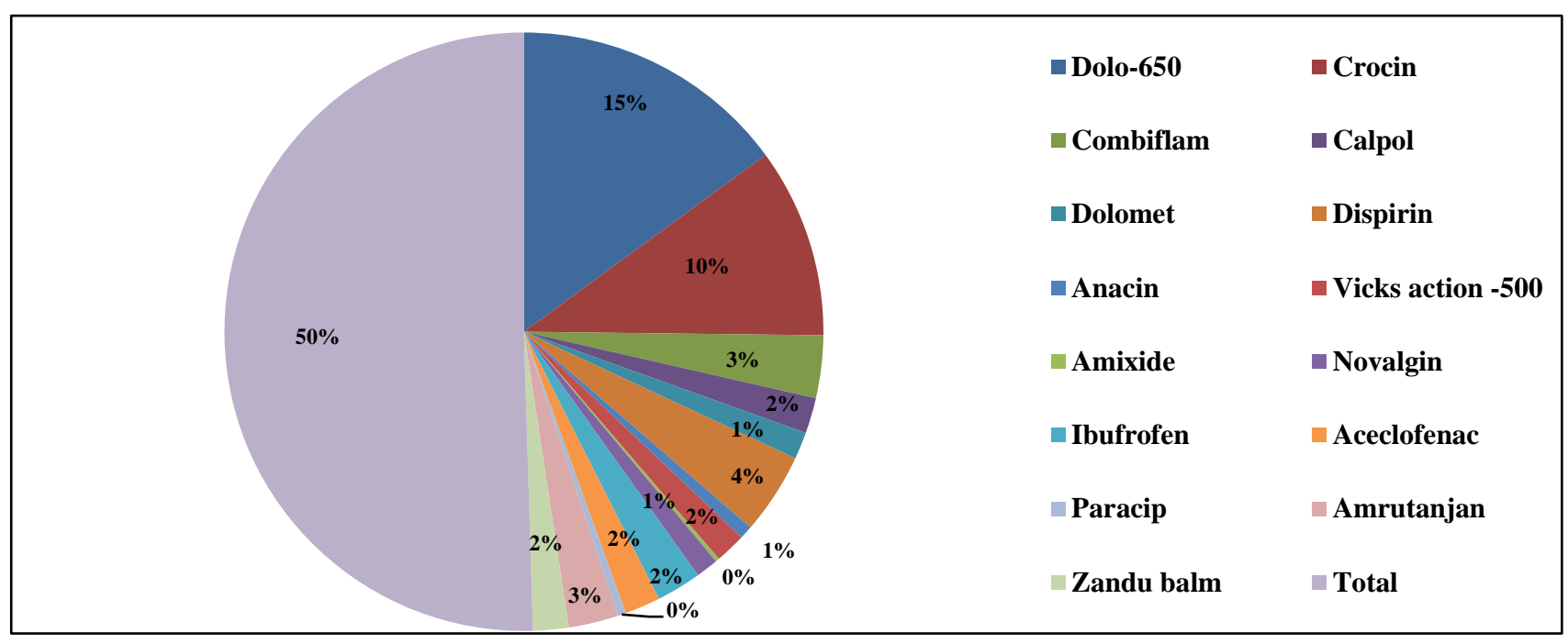

Figure 7: Drugs for fever and headache.

\section{Drugs used for eye and ear infections}

$41.7 \%$ participants used ciprofloxacin, $16.01 \%$ used gentamycin drops, $9.2 \%$ used sulfacetamide eye drops, $11.65 \%$ used A-flox drops, $24 \%$ used dexamethasone drops, $9.2 \%$ used cirowax, 5.3\% used murine ear wax, $4.3 \%$ used ring relief ear wax (Figure 8).

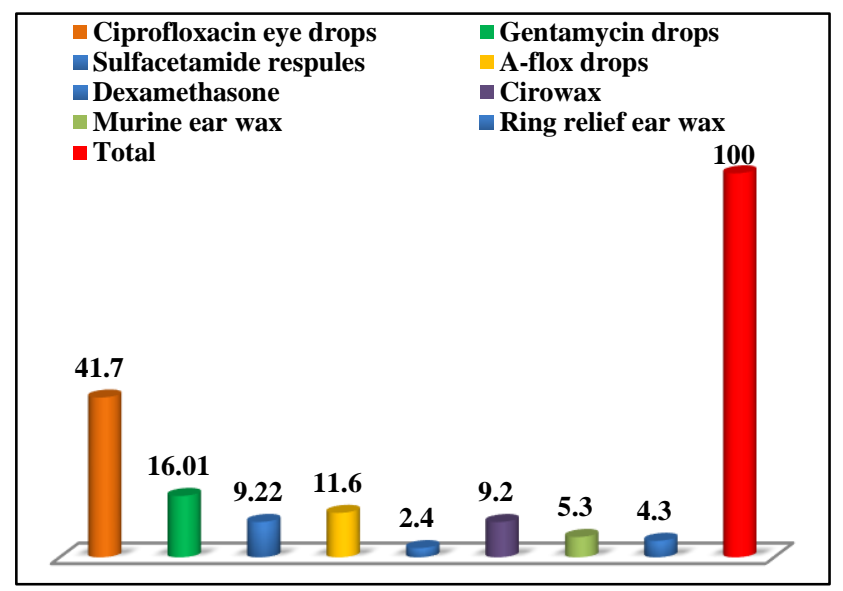

Figure 8: Drugs for eye/ear infection.

\section{Drugs used for GI infections}

$26.6 \%$ used gelusil, $20.3 \%$ used ORS, $9.2 \%$ used electoral powder, $2.9 \%$ used pudinhara, $5.3 \%$ used metrogyl, $4.3 \%$ used albendazole, $4.8 \%$ used meftal spas, $3.3 \%$ used domperidone, $1.4 \%$ used senna, $4.3 \%$ used bisacodyl, $8.7 \%$ used rantac tablets, $4.3 \%$ used diegene, $3.8 \%$ used $1-$ doper (Figure 9).

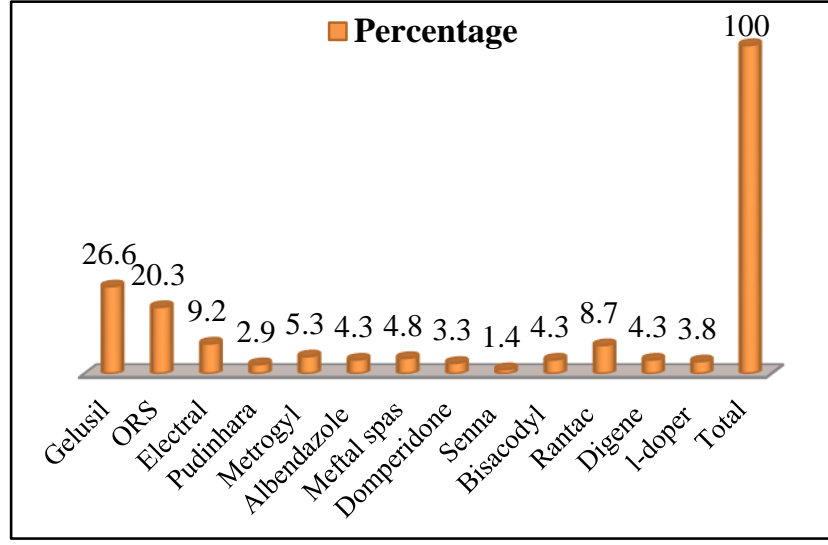

Figure 9: Drugs for GIT infections.

\section{Drugs used for skin and related infections}

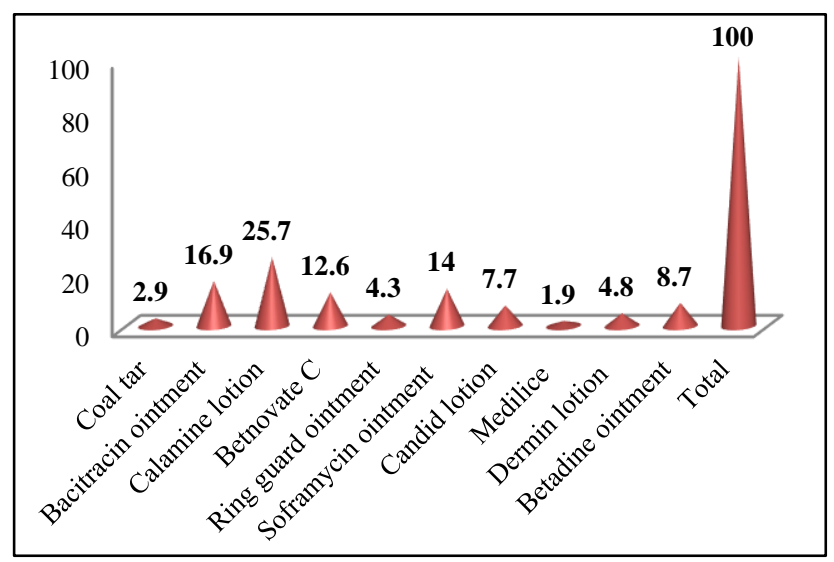

Figure 10: Drugs for skin and related infections. 
$2.9 \%$ used coal tar, $16.9 \%$ used bacitracin ointment, $25.7 \%$ used calamine lotion, $12.6 \%$ used betnovate $\mathrm{C}, 4.3 \%$ used ring guard ointment, $14 \%$ used soframycin cream, 7.75 used candid lotion, $1.9 \%$ used medlice, $4.8 \%$ used dermin lotion, $8.7 \%$ used betadine ointment as self medication (Figure 10).

\section{Other medications used}

Other medications used as a part of self medications i.e. $16 \%$ used vitaflor, $48 \%$ used turmeric, $22 \%$ used homeopathy tinctures and 14\% used Ayurveda extracts (Figure 11).

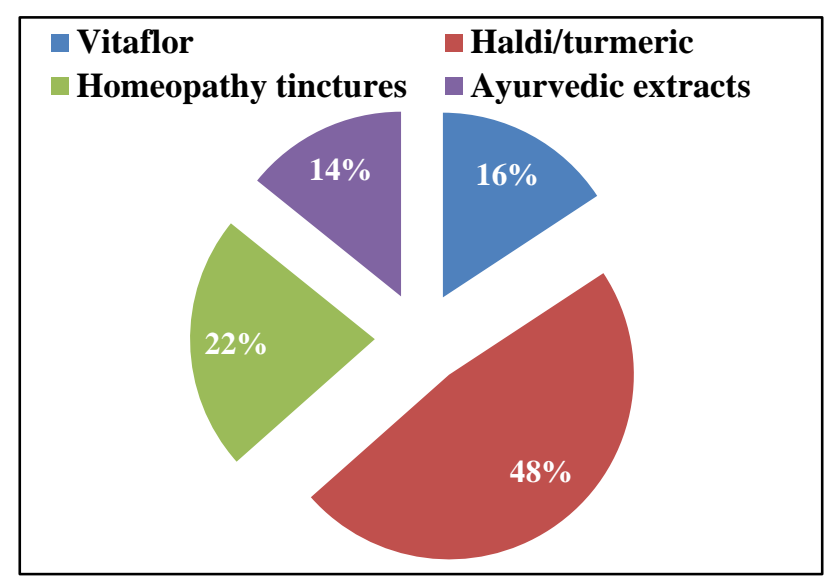

Figure 11: Other medications.

\section{DISCUSSION}

According to World Health organization, self medication is the selection and use of medicines by individuals to self diagnosed or recognized illness or symptoms. ${ }^{18}$ Self medication by itself determines the pattern and intensity of use of medications which depend on who and what one chooses to self medicate irrespective of their profession. ${ }^{19}$ The present study was conducted to evaluate the prevalence of self medication in common illness among non health care professionals in a tertiary care hospital. The prevalence of self medication was found to be $96 \%$ in our study (Figure 1). Other studies on Indian non-medical background showed a prevalence of $80 \%$ in Tamilnadu. ${ }^{20}$ and $87 \%$ in Uttar Pradesh. ${ }^{21}$ The prevalence of self medication was observed to be higher among males in our study as many observations made in studies from india included females. ${ }^{22}$ Majority of the participants followed allopathy system of medicine (Figure 4) and majority of them self medicated use of turmeric for other common disorders like minor wounds, abrasions etc (Figure 11). Which is similar to observations made in other studies from India. ${ }^{21,23}$ Majority of the participants obtained the information regarding self medication from pharmacist $(30 \%)$ (Figure 3). For treatment of mouth and throat ulcer mucaine gel and becosules tablets were highly self medicated by the participants (16\%) (Figure 5). For the treatment of cough and common cold D-cold total tablets were highly used by the participants (26\%) (Figure 6). For treatment of fever and headache majority of the participants self medicated Dolo 650mg (15\%) (Figure 7). For treatment of eye and ear infections majority of the participated self medicated ciprofloxacin antibiotic $(41.7 \%)$ (Figure 8). Irrespective of specific Gastro intestinal infection majority of the participants self medicated gelusil syrup (26.6\%) (Figure 9). For skin and related infections calamine lotion was self medicated by most of the participants (25.7\%) (Figure 10). In the present study $47.5 \%$ of participants felt that self medication was taken as they found the disease/illness was very simple. $68.4 \%$ participants took medicines occasionally as a part of self medication not very regularly. More than $50 \%$ of the participants wish to continue the self medication without consulting a respective physician. More than $50 \%$ of participants were not aware of the duration of use of medication, adverse effects of these medicines and they even lack the knowledge about the banned drugs in India irrespective of which they continued to use due to their availability in the market. In the present study, though common medicines are self medicated for common illness the irrational use of these drugs can result in accidental drug poisoning. Other consequences related to self medication are related to serious health hazards such as adverse drug reactions and drug dependence. ${ }^{23}$ The study findings are based on single centric study conducted at hyderabad has to be included. Hence, study observations cannot be generalized based on single centric study has to be included. More multicentric studies need to be carried out among non-health care professionals at large to understand the various factors for self medications.

\section{CONCLUSION}

It has been observed in this study that majority of the participants used a particular medicine for similar symptoms. One of the possible reasons for this may be that all study participants work in same set-up and may be discussing their disease symptoms and medicines used. The present study suggests the growing trend of self medication has to be prevented by applying strong policies and prohibiting the supply of medicines without a valid prescription.

\section{ACKNOWLEDGEMENTS}

Authors would like to acknowledge to the Institutional Human Ethics committee and for all the study participants working in the tertiary care hospital for their active participation. Also acknowledge Dr. Sushma, Associate Professor of SPM Department for her kind suggestions in preparing the questionnaire pattern and helping in statistical analysis of data.

\section{Funding: No funding sources \\ Conflict of interest: None declared}

Ethical approval: The study was approved by the Institutional Human Ethics Committee of Malla Reddy Institute of Medical Sciences, Hyderabad (IHEC/MRIMS/15/2016) 


\section{REFERENCES}

1. Hughes CM, McElnay JC, Fleming GF. Benefits and risks of self medication. Drug safe 2003;24:1027-37.

2. Bowen D, Kisuule G, Ogasawara H, Siregar ChJP, Williams GA. Guidelines for the Regulatory Assessment of Medicinal Products for use in self medication (PDF). 2000. WHO/EDM/QSM/00.1 Geneva: WHO, retrieved 2012-09-02.

3. Shankar PR, Partha P, Shenoy N. Self-Medication and non doctor prescription practices in Pokhara valley, Western Nepal: A questionaire based study. A questionnaire based study. BMC FAM Pract. 2002;3:17. Available at: http://www.pubmedcentral.nih.gov/articlerender.fcgi ?artid=130019.

4. Montastruc JL, Bagheri H, Geraud T, Lapeyre-Mestre M. Pharmacovigilance of self medication Therapie. 1997;52:105-10.

5. Khantzian EJ, Mack JF, Schatzberg AF. American Journal of Psychiatry. 1974;131:160-4.

6. Duncan DF. Reinforcement of drug abuse: Implications for prevention. Clinical Toxicology Bulletin. 1974;4:69-75.

7. Khantzian EJ. The self medication hypothesis of drug use disorders: A reconsideration and recent applications. Harvard Review of Psychiatry. 1997;4:231-44.

8. Khantzian EJ. Treating addiction as a human process. Northvale, NJ: Jason Aronson; 1999.

9. Selvaraj K, Kumar SG, Ramalingam A. Prevalence of self medication practices and its associated factors in urban puducherry, India. Perspect Clin Res. 2014;5:32-6.

10. Balamurugan E, Ganesh K. Prevalence and pattern of self medication use in costal regions of South India. BJMP. 2011;4(3):A428.

11. Choorna I, Gill A, Nunn A. Drug toxicity and surveillance in children. British Journal Of Clinical Pharmacology. 1996;42:407-10.

12. Kumar DB, Raghuram TC, Radhaiah G, Krishnaswamy. Profile of drug use in urbam and rural India, Pharmacoeconomics. 1995;7:332-46.

13. LiL J, Wang Ps. Self medication with antibiotics: A possible cause of bacterial resistance. Med Hypothesis. 2005;65:100-1. (Pub Med).
14. Figueiras A. Caamano F, Gestal-otero JJ. Sociodemographic factors related to self medication in spain. Eur J Epidemiol. 2000;16;19-26.

15. Martins AP, Miranda AC, Mendes Z Soares MA, Ferreira P, Nogueira A: Self medication in a Portuguese urban population: A perspective study pharmacoepidemiol drug safety. 2002;11:409-14.

16. Aljinovic-vucicv, Trkulja V, Lackovicz. Content of home pharmacies and self medication practices house hold of pharmacy and medical students in Zagreb, Croatia: Findings in 2001 with reference to 1997. Croat Med J. 2005;46:74-80.

17. The Role OF the Pharmacist in self care and self medication. Available at: http://apps.who.int/medicinedocs/pdf/who.zip32e.pdf Accessed:2013Feb27.

18. Dangers of self medication Available at: http//www.healthguidance.Org/entry/15933/1/Danger s -of-self-medication.html. Accessed:2013feb28.

19. Kayalrizhi S, Senapathi R. Evaluation of the perception, attitude and practice of self medication among business students in 3 select cities, South India. IJEIMS. 2010;1(3):40-4.

20. Verma RK, Mohan L, Pandey M. Evaluation of self medication among professional students in North India: Proper statutory drug control must be implemented. Asian J pharmaceutical Clin Res. 2010;3(1)60-4.

21. Banerjee I, Bhadury T. Self medication practice among undergraduate medical students in a tertiary care medical college, West Bengal J Post Grad Med. 2012;58(2):127-31.

22. Gupta V, Bansal P, Manhas R. Singh Z, Ghaiye P. Prefered system of medicine and reasons of self medication among college students in Malwa region of Punjab. J Drug Deliv and Ther. 2011;1(2):27-9.

23. Sarkar P, Gould IM. A ntimicrobial agents are societal drugs: how should this influence prescribing? Drugs. 2006;66(7):893-901.

Cite this article as: Guduru J, Singh TR, Motgi S, Rani J. Evaluation of self medication practices in common illness among non health care professionals in a tertiary care hospital. Int $\mathbf{J}$ Basic Clin Pharmacol 2017;6:2311-6. 